\title{
ANTHOCYANIN-RICH EXTRACT DECREASES INDICES OF LIPID PEROXIDATION AND DNA DAMAGE IN VITAMIN E-DEPLETED RATS
}

\author{
Carmen Ramirez-Tortosa, ${ }^{* \dagger}$ Øyvind M. Andersen, ${ }^{*}$ Peter T. Gardner, ${ }^{*}$ Philit C. Morrice, ${ }^{*}$ \\ Sharon G. Wood, * Susan J. Duthie,* Andrew R. Collins,* and Garry G. Duthie* \\ *Antioxidants and DNA Damage Group, Rowett Research Institute, Aberdeen, Scotland, UK; 'Instituto de Nutricion y Tecnología \\ de Alimentos, Departamento de Bioquimica y Biologia Molecular, Universidad de Granada, Granada, Spain; and ${ }^{*}$ Department of \\ Chemistry, University of Bergen, Bergen, Norway
}

(Received 21 February 2001; Accepted 22 May 2001)

\begin{abstract}
Anthocyanins are secondary plant metabolites responsible for the blue, purple, and red color of many plant tissues. The phenolic structure of anthocyanins conveys marked antioxidant activity in model systems via donation of electrons or hydrogen atoms from hydroxyl moieties to free radicals. Dietary intakes of anthocyanins may exceed 200 $\mathrm{mg} /$ day, however, little is known about their antioxidant potency in vivo. Consequently, the aim of this study was to establish whether anthocyanins could act as putative antioxidant micronutrients. Rats were maintained on vitamin E-deficient diets for 12 weeks in order to enhance susceptibility to oxidative damage and then repleted with rations containing a highly purified anthocyanin-rich extract at a concentration of $1 \mathrm{~g} / \mathrm{kg}$ diet. The extract consisted of the 3-glucopyranoside forms of delphinidin, cyanidin, petunidin, peonidin, and malvidin. Consumption of the anthocyaninrepleted diet significantly improved $(p<.01)$ plasma antioxidant capacity and decreased $(p<.001)$ the vitamin E deficiency-enhanced hydroperoxides and 8-Oxo-deoxyguanosine concentrations in liver. These compounds are indices of lipid peroxidation and DNA damage, respectively. Dietary consumption of anthocyanin-rich foods may contribute to overall antioxidant status, particularly in areas of habitually low vitamin E intake. (C) 2001 Elsevier Science Inc.
\end{abstract}

Keywords-Anthocyanins, Polyphenols, Vitamin E deficiency, Lipid peroxides, DNA damage, Antioxidants, Free radicals

\section{INTRODUCTION}

Many polyphenolic products of the phenylpropanoid biosynthetic pathway in plants have considerable antioxidant ability in vitro. This is due to the ease with which an $\mathrm{H}$-atom from an aromatic hydroxyl group of polyphenols can be donated to a free radical, and the ability of the aromatic group to then support the unpaired electron via delocalization around the $\pi$-electron system [1]. In addition, many polyphenols can bind transition metal ions thus preventing the formation of reactive species by Fenton chemistry [2]. There are no known deficiency states resulting from lack of plant polyphenols. Therefore, even though dietary intakes may exceed $1 \mathrm{~g} /$ day [3], they have generally been regarded as non-nutritive.

Address correspondence to: Dr. Garry G. Duthie, Rowett Research Institute, Greenburn Road, Bucksburn, Aberdeen, AB21 9SB, UK; Tel: +44 (1224) 716-623; Fax: +44 (1224) 716-622; E-Mail: ggd@rri. sari.ac.uk.
However, epidemiological studies inversely relating intakes of flavonols and flavones with the incidence of heart disease (for recent review, see ref. [4]) may indicate a putative role for certain polyphenols in the prevention of chronic diseases that involve oxidative processes.

Countries in Northern latitudes generally have the greatest number of premature deaths from chronic diseases such as coronary heart disease and strokes [5]. This is ascribed, in part, to a habitually low consumption of foods rich in antioxidant micronutrients [6]. For example, in such countries more than $95 \%$ of the population may not achieve the U.S. recommended daily allowance for vitamin E [7]. This may be due to traditional dietary patterns and the expense and lack of availability of fresh fruit and vegetables. For such populations, a potentially important source of antioxidant-rich food may be locally grown soft fruits (e.g., raspberries, blueberries, cranberries, and blackcurrent). These are rich in anthocyanins, which are glycosidic-linked flavonoids responsible for 

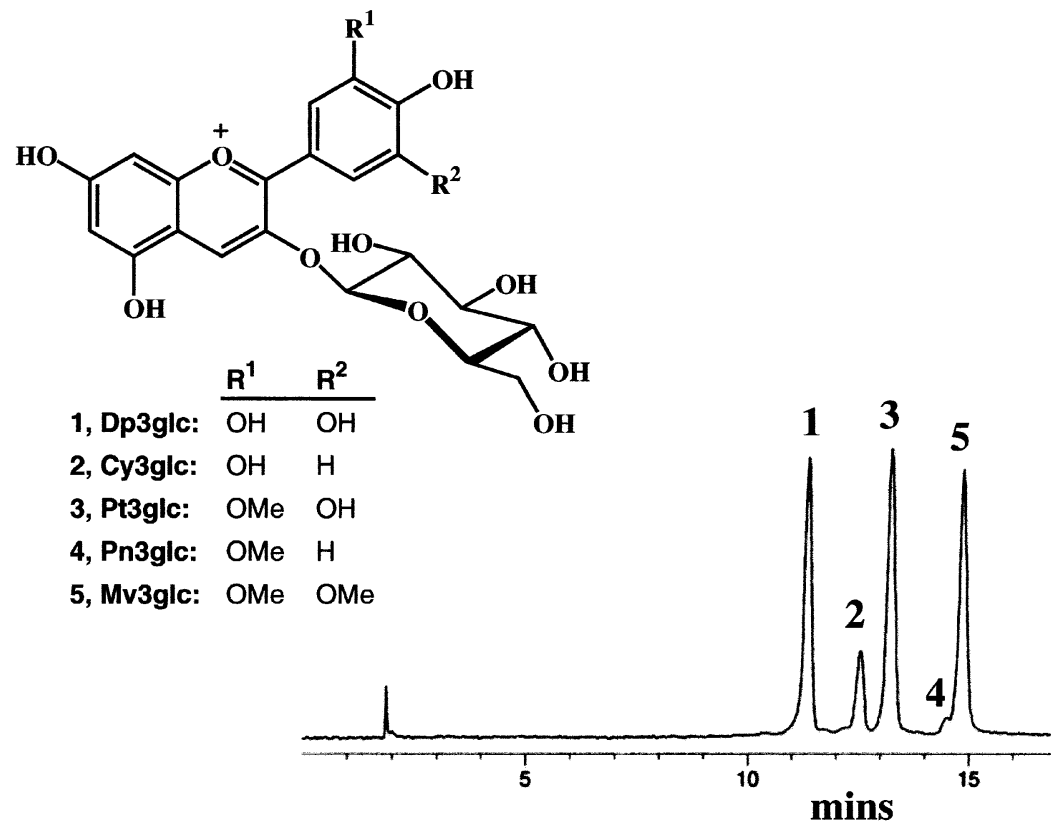

Fig. 1. HPLC profile of the purified anthocyanin sample from Abies procera detected at $520 \pm 20 \mathrm{~nm}$. The structures of the anthocyanins are also shown: $1-5$. Dp = delphinidin; $\mathrm{Cy}=$ cyanidin; $\mathrm{Pt}=$ petunidin; $\mathrm{Pn}=$ peonidin; $\mathrm{Mv}=$ malvidin and glc $=$ glucose. Measurement was performed on a HP-1050 module system (Hewlett Packard) using an ODS Hypersil column $(200 \times 4.6 \mathrm{~mm}$, $5 \mu \mathrm{m})$ and diode array detection. The two solvents used for elution were: (A) $\mathrm{HCO}_{2} \mathrm{H}-\mathrm{H}_{2} \mathrm{O}$ (1: 9, v/v) and (B) $\mathrm{MeOH}_{-} \mathrm{HCO}_{2} \mathrm{H}-\mathrm{H}_{2} \mathrm{O}$ (5: 1: 4, v/v). The elution profile was $0-4 \mathrm{~min}, 10 \% \mathrm{~B}$ in A (isocratic); 4-21 min, 10-100\% B in A (linear gradient), 100\% B (isocratic) for the next $4 \mathrm{~min}$ followed by linear gradient back to $10 \% \mathrm{~B}$ in $1 \mathrm{~min}$. The flow rate was $1.2 \mathrm{ml} \mathrm{min}{ }^{-1}$, and aliquots of $15 \mu \mathrm{l}$ were injected. Prior to injection the samples were filtered through a $0.45 \mu \mathrm{m}$ Millipore membrane filter. UV-VIS absorption spectra were recorded on-line using a photodiode array detector (HP 1050, Hewlett-Packard).

the red, violet, purple, and blue colors of many plants [8]. As with other plant polyphenols, many anthocyanins have marked antioxidant activity in vitro $[9,10]$. Some anthocyanins are bioavailable, as they have been detected in human plasma, however, little is known about their potential antioxidant properties in vivo $[11,12]$. Consequently, in order to ascertain whether anthocyanins can act as putative antioxidant nutrients, we have repleted rats previously maintained on vitamin $\mathrm{E}$ deficient rations with either a highly purified anthocyanin extract or $\mathrm{d} \alpha$-tocopherol. The aim was to assess the ability of the anthocyanin extract to modify the elevated indices of oxidative damage induced by vitamin E deficiency.

\section{MATERIALS AND METHODS}

\section{Anthocyanin extract}

To prepare the anthocyanin extract, the scraped surface material from the cones of Abies koreana $(800 \mathrm{~g})$ was extracted with 11 of $90 \% \mathrm{MeOH}$ containing $0.1 \%$ $\mathrm{HCl} 0.5 \mathrm{M}$ citric acid. The procedure was repeated five times and the combined extracts were then filtered, concentrated under reduced pressure at $25^{\circ} \mathrm{C}$, partitioned against ethyl acetate, and applied to an Amberlite XAD-7 column [13]. The column was washed with water and the sample was eluted with $\mathrm{MeOH} 0.1 \% \mathrm{HCl}$. The eluant was dried under reduced pressure. The purity of the sample $(10.9 \mathrm{~g})$ was checked by HPLC using simultaneous detection at $520 \pm 20$ and $280 \pm 10 \mathrm{~nm}$ (for conditions, see legend of Fig. 1). Both chromatograms revealed only previously identified anthocyanins [14], which were the 3-glucosides of delphinidin, cyanidin, petunidin, peonidin, and malvidin, respectively (Fig. 1), their relative proportions in the extract being $30,10,32$, 2 , and $26 \%$, respectively.

\section{Animals and diets}

Individually housed weanling male rats of the Rowett Hooded Lister strain were offered, ad libitum, a semisynthetic diet containing less than $0.5 \mathrm{mg} / \mathrm{kg}$ vitamin $\mathrm{E}$ [15]. After 10 weeks, the rats were then offered the diet containing either $\mathrm{d} \alpha$-tocopherol or the dried anthocyanin extract at a concentration of $1 \mathrm{~g} / \mathrm{kg}$ diet for a further 2 weeks (six rats in each group). The extract was finely ground and mixed to an even distribution in the diets. Six rats continued to be offered the vitamin $\mathrm{E}$ deficient ration and six the vitamin $\mathrm{E}$ adequate ration throughout the trial. Diets were stored at $-40^{\circ} \mathrm{C}$ until use.

Rats were anesthetized with halothane and blood re- 
Table 1. Effect of Vitamin E Deficiency and then 2 Weeks Repletion with the Anthocyanin Extract or Vitamin E on Rat Weight, Plasma, and Liver $\mathrm{d} \alpha$-Tocopherol Concentrations and Plasma Antioxidant Capacity

\begin{tabular}{|c|c|c|c|c|}
\hline Parameter & $\begin{array}{c}\text { Vitamin } \\
\text { E-sufficient diet }\end{array}$ & $\begin{array}{c}\text { Vitamin } \\
\text { E-deficient diet }\end{array}$ & $\begin{array}{c}\text { Vitamin E-deficient } \\
\text { diet }+ \text { anthocyanin extract }\end{array}$ & $\begin{array}{l}\text { Vitamin E-deficient } \\
\text { diet }+\mathrm{d} \alpha \text {-tocopherol }\end{array}$ \\
\hline Weight $(\mathrm{g})$ & $382 \pm 7$ & $389 \pm 8$ & $394 \pm 10$ & $398 \pm 6$ \\
\hline Plasma d $\alpha$-tocopherol $(\mu \mathrm{g} / \mathrm{ml})$ & $8.7 \pm 0.3$ & nd & nd & $8.1 \pm 0.5$ \\
\hline Liver $\mathrm{d} \alpha$-tocopherol ( $\mu \mathrm{g} / \mathrm{g}$ protein) & $370 \pm 34$ & nd & nd & $334 \pm 62$ \\
\hline $\begin{array}{l}\text { Plasma antioxidant capacity } \\
\text { (\% radicals reduced })\end{array}$ & $46 \pm 2$ & $32 \pm 2^{\mathrm{a}}$ & $38 \pm 1^{c}$ & $46 \pm 1^{b}$ \\
\hline
\end{tabular}

\footnotetext{
${ }^{\mathrm{a}}$ Significant effect of vitamin $\mathrm{E}$ deficiency, $p<.001 ;{ }^{\mathrm{b}}$ significant effect of repletion with $\mathrm{d} \alpha$-tocopherol, $p<.001 ;{ }^{\mathrm{c}}$ significant effect of repletion with anthocyanin, $p<.01$. Data as mean \pm SEM, 6 rats/group. nd $=$ not detectable.
}

moved by cardiac puncture into heparinized evacuated tubes (Becton Dickinson, Oxford, UK). Plasma was obtained by centrifugation $\left(2500 \times g, 10 \mathrm{~min}, 4^{\circ} \mathrm{C}\right)$ and red cells were washed twice prior to being resuspended to the original volume in $\mathrm{NaCl}(0.9 \%)$. Livers were perfused in situ with chilled $0.15 \mathrm{M} \mathrm{KCl}$ and hepatic microsomes were prepared by the method of Lim et al. [16]. Plasma and the remaining liver tissue were immediately snap frozen in liquid nitrogen and stored at $-70^{\circ} \mathrm{C}$.

\section{Biochemical analysis}

Vitamin E concentrations in plasma and liver were determined by reverse phase HPLC with fluorimetric detection [17] under the auspices of the U.S. National Institute of Standards Quality Assurance Scheme for fat-soluble vitamins. The antioxidant capacity of plasma was estimated by its ability to donate a hydrogen atom or electron to the synthetic free radical, potassium nitrosodisulphonate (Fremy's salt) detected by electron spin resonance (ESR) spectroscopy [18]. In brief, $50 \mu \mathrm{l}$ of a 10 -fold dilution of plasma was mixed with an equal volume of Fremy's salt $[0.05 \mathrm{mM}$ in $10 \mathrm{ml}$ phosphatebuffered saline(PBS)] and the spectrum of the low field resonance of the Fremy's radical was recorded after 5 min. Spectra were obtained at $21^{\circ} \mathrm{C}$ on a Bruker ECS 106 spectrometer working at ca. $9.5 \mathrm{GHz}$ (X-band frequency) and equipped with a cylindrical $\left(\mathrm{TM}_{110}\right.$ mode) cavity. The microwave power and modulation amplitude were set at $2 \mathrm{~mW}$ and $0.01 \mathrm{mT}$, respectively. The number of Fremy's radicals reduced by the plasma was compared with that of a control reaction using PBS instead of diluted plasma. Endogenous hydroperoxide concentrations in liver homogenates were determined by the ferrous orange xylenol method as described in Jiang et al. [19]. DNA damage in the liver was estimated from the amount of 8-Oxo-deoxyguanosine (8-Oxo-dG) present. This was determined by HPLC using electrochemical detection following extraction procedures designed to minimize artifactual oxidation of the DNA [20]. The susceptibility of hepatic microsomal preparations to ox- idation in vitro was assessed by the production of thiobarbituric acid reactive substances (TBARS) following incubation $\left(4 \mathrm{~min}, 37^{\circ} \mathrm{C}\right)$ with $30 \mu \mathrm{M} \mathrm{FeSO} 4.7 \mathrm{H}_{2} \mathrm{O}$, $2 \mathrm{mM}$ ADP and $0.5 \mathrm{mM}$ L-ascorbic acid [21]. Susceptibility of washed erythrocytes to peroxidation was also estimated by the formation of TBARS following $20 \mathrm{~min}$ incubation at $37^{\circ} \mathrm{C}$ with $0.1 \mathrm{M}$ hydrogen peroxide [21].

Results are presented as mean \pm SEM. Data was initially analyzed by one-way analysis of variance and comparison of groups was made using the Bonferroni Multiple Comparison test. A $p$ value of less than .05 was considered significant.

\section{RESULTS}

Final rat weights in all groups were similar and unaffected by the tocopherol or anthocyanin contents of the diets. Following consumption of vitamin E-deficient diets for 10 weeks, plasma and liver $\mathrm{d} \alpha$-tocopherol concentrations were below detectable levels $(<0.5 \mu \mathrm{g} / \mathrm{ml}$ and $<5 \mu \mathrm{g} / \mathrm{g}$ protein for plasma and liver, respectively). In the rats repleted for 2 weeks with diet containing $\mathrm{d} \alpha$-tocopherol, concentrations were similar to those animals maintained throughout the trial on the vitamin E-sufficient rations (Table 1). Vitamin E deficiency was also associated with a 30\% decrease $(p<.001)$ in plasma antioxidant capacity. Repletion with diet containing the anthocyanin-rich extract significantly enhanced $(p<.01)$ plasma antioxidant capacity, but to a lesser extent than in those rats repleted with vitamin E (Table 1). Consumption of vitamin $\mathrm{E}$ deficient rations for 10 weeks was also associated with an increase of hydroperoxides $(p<.001)$ and 8-Oxo-dG $(p<.001)$ in liver, an effect which was markedly less in rats repleted with either the anthocyanin-rich extract or $\mathrm{d} \alpha$-tocopherol (Fig. 2). However, analogous protection against oxidative damage was not observed when microsomes and red cells from rats consuming the anthocyanin-rich extract were incubated with Fe/ADP and $\mathrm{H}_{2} \mathrm{O}_{2}$, respectively. This contrasted with the highly protective effect observed as a result of repletion with $\mathrm{d} \alpha$-tocopherol (Table 2). 

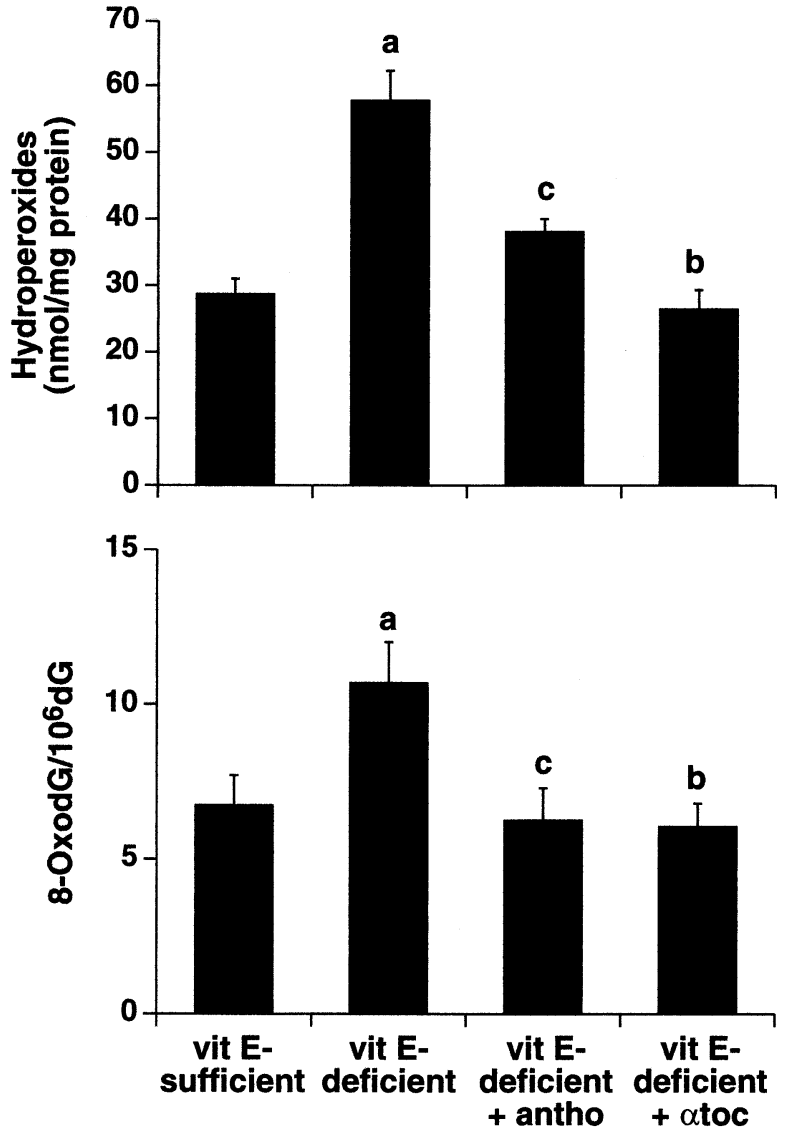

Fig. 2. Effect of vitamin $\mathrm{E}$ depletion and 2 weeks repletion with the anthocyanin extract or vitamin $\mathrm{E}$ on liver concentrations of 8-Oxo-dG and lipid hydroperoxides.

\section{DISCUSSION}

It has long been known that vitamin E deficiency results in increased indices of lipid peroxidation in blood and tissues of animals. Moreover, repletion with vitamin E can rapidly reverse the biochemical and clinical symptoms of vitamin E deficiency, provided that the deficiency state is not excessively prolonged. However, as far as we can ascertain, this is the first report to demonstrate that vitamin E deficiency also increases oxidative damage to DNA as estimated by concentrations of
8-Oxo-dG, and that basal levels can be subsequently restored by reintroduction of vitamin E to the diet. Such damage to DNA may produce mutations that cause permanent alterations in the genetic message when the cell replicates its DNA and thus increases risk of carcinogenesis. These results therefore support recent epidemiological studies implicating low intakes or blood levels of vitamin $\mathrm{E}$ with the subsequent risk of cancers at various sites [22-25].

Consumption of the anthocyanin-rich extract also moderated elevated indices of oxidative DNA damage in liver. Whether this effect is ascribed to free radical scavenging, upregulation of DNA repair mechanisms and antioxidant enzymes, or the formation of protective anthocyanin-DNA co-pigmentation complexes [26] is unclear. However, analogous effects on concentration of hydroperoxides in liver and on plasma antioxidant capacity also suggest that the anthocyanin-rich extract possesses antioxidant activity in vivo. The apparent ability of the strongly polar anthocyanins to substitute for the lipophilic antioxidant, vitamin E, may be analogous to the ability of vitamin $\mathrm{C}$ to protect biomembranes from peroxidation by efficiently trapping peroxyl radicals in the cytosol [27]. Alternatively, the antioxidant effect may reflect, in part, the ability of polyphenols, including anthocyanins, to chelate transition metal ions involved in radical-forming processes such as Fenton reactions [28].

Direct intestinal absorption of anthocyanins in the intact glycoside form and subsequent biotransformation to methylated derivatives in the liver has been observed in the rat [11]. This suggests that the anthocyanins in the highly purified extract are also bioavailable. However, tissue concentrations of anthocyanins and related metabolites were not measured in the present study and therefore it is unclear which of the compounds in the extract has the most marked antioxidant effect in vivo.

The possibility that the marked in vivo antioxidant effects of this highly-purified extract are due to the presence of other unidentified compounds apart from the anthocyanins is unlikely but cannot be excluded. The HPLC profile (Fig. 1) is detected at $520 \pm 20 \mathrm{~nm}$. The HPLC profile detected simultaneously at $280 \pm 10 \mathrm{~nm}$

Table 2. Susceptibility of Red Cells and Hepatic Microsomal Preparations from Rats Maintained on Vitamin E-Deficient Rations, then Repleted for 2 Weeks with the Anthocyanin Extract or Vitamin E or Maintained on a Vitamin E-Sufficient Ration throughout the Trial

\begin{tabular}{lcccc}
\hline Parameter & $\begin{array}{c}\text { Vitamin } \\
\text { E-sufficient diet }\end{array}$ & $\begin{array}{c}\text { Vitamin } \\
\text { E-deficient diet }\end{array}$ & $\begin{array}{c}\text { Vitamin E-deficient } \\
\text { diet }+ \text { anthocyanin extract }\end{array}$ & $\begin{array}{c}\text { Vitamin E-deficient } \\
\text { diet }+ \text { d } \alpha \text {-tocopherol }\end{array}$ \\
\hline $\begin{array}{l}\text { Red cells (nmol TBARS/g Hb) } \\
\text { Hepatic microsomes (nmoles }\end{array}$ & $83 \pm 7$ & $809 \pm 33^{\mathrm{a}}$ & $801 \pm 40$ & $79 \pm 7^{\mathrm{b}}$ \\
TBARS/mg protein) & $1.3 \pm 0.4$ & $25.8 \pm 0.4^{\mathrm{a}}$ & $23.1 \pm 0.5$ & $0.9 \pm 0.2^{\mathrm{b}}$ \\
\hline
\end{tabular}

\footnotetext{
${ }^{\mathrm{a}}$ Significant effect of vitamin E deficiency, $p<.001{ }^{\mathrm{b}}$ significant effect of repletion with $\mathrm{d} \alpha$-tocopherol, $p<.001$. Data as mean $\pm \mathrm{SEM}, 6$
} rats/group. TBARS $=$ thiobarbituric acid reactive substances; $\mathrm{Hb}=$ hemoglobin. 
shows exactly the same pattern. This suggests that there are no compounds present other than the anthocyanins, although there is the possibility that there are compounds which are not absorbing light in the region between 270 and $600 \mathrm{~nm}$. However, the extract did not contain detectable amounts of vitamin $\mathrm{E}$, vitamin $\mathrm{C}$, or carotenoids, which are generally recognized as important antioxidant micronutrients.

Unlike vitamin E repletion, consumption of the anthocyanin-rich extract did not decrease the susceptibility of microsomal preparations or washed red cells to oxidize ex vivo. This may indicate that anthocyanins are less strongly intercalated in the cell membranes than vitamin $\mathrm{E}$ and were therefore lost during the preparation of the microsomes and red cells. Similar effects have been reported during the preparation of low-density lipoprotein from plasma of polyphenol-supplemented human volunteers [29], and indicates that in intervention trials important biological effects may be lost through manipulation of samples ex vivo.

In conclusion, an anthocyanin-rich extract containing the 3-glucopyranoside forms of delphinidin, cyanidin, petunidin, and malvidin markedly decreased vitamin $\mathrm{E}$ deficiency-induced elevations in DNA damage and hydroperoxides in liver and increased plasma antioxidant capacity. As anthocyanins are widespread in many fruit and vegetable species, both wild and horticultural cultivars may be an important source of antioxidant phytochemicals in populations with habitually low intakes of the recognized antioxidant micronutrients.

Acknowledgements - We are grateful for financial support from the Scottish Executive Rural Affairs Department, the University of Granada, Spain, and the EU Framework V programme.

\section{REFERENCES}

[1] Rice-Evans, C. A.; Miller, N. J.; Paganga, G. Structure-antioxidant activity relationships of flavonoids and phenolic-acids. Free Radic. Biol. Med. 20:933-956; 1996.

[2] Yoshino, M.; Murakami, K. Interaction of iron with polyphenolic compounds: application to antioxidant characterization. Anal. Biochem. 257:40-44; 1998.

[3] Formica, J. V.; Regelson, W. Review of the biology of quercetin and related bioflavonoids. Food Chem. Toxicol. 33:1061-1080; 1995.

[4] Duthie, G. G.; Duthie S. J.; Kyle, J. A. M. Plant polyphenols in cancer and heart disease: implications as nutritional antioxidants. Nutr. Res. Rev. 13:79-106; 2000.

[5] Bellizzi, M. C.; Franklin, M. F.; Duthie, G. G.; James, W. P. T. Vitamin $\mathrm{E}$ and coronary heart disease: the European paradox. Eur. J. Clin. Nutr. 48:822-831; 1994.

[6] Diplock, A. T. Antioxidants and disease prevention. Mol. Aspects Med. 15:293-376; 1994.

[7] Duthie, G. G.; Arthur, J. R.; Beattie, J. A. G.; Brown, K. B.; Morrice, P. C.; Robertson, J. D.; Shortt, C. T.; Walker, K. A.; James, W. P. T. Cigarette smoking, antioxidants, lipid peroxidation and coronary heart disease. Ann. N. Y. Acad. Sci. 686:120129; 1993.

[8] Clifford, M. N. Anthocyanins-nature, occurrence and dietary burden. J. Sci. Food Agric. 80:1063-1072; 2000.
[9] Wang, H.; Cao, G. H.; Prior, R. L. Oxygen radical absorbing capacity of anthocyanins. J. Agr. Food. Chem. 45:304-309; 1997.

[10] Tsuda, T.; Shiga, K.; Ohshima, K.; Kawakishi, S.; Osawa, T. Inhibition of lipid peroxidation and the active oxygen radical scavenging effect of anthocyanin pigments isolated from Phaseolus vulgaris. Biochem. Pharmacol. 52:1033-1039; 1996.

[11] Miyazawa, T.; Nakagawa, K.; Kudo, M.; Kayo, M.; Someyo, K. Direct intestinal absorption of red fruit anthocyanins, cyanidin-3glucoside and cyanidin-3-5-diglucoside, into rats and humans. $J$. Agric. Food Chem. 47:1083-1091; 1999.

[12] Cao, G.; Prior, R. L. Anthocyanins are detected in human plasma after oral administration of an elderberry extract. Clin. Chem. 45:574-576; 1999.

[13] Andersen, $\varnothing$. M. Semipreparative isolation and structure determination of pelargonidin 3-O- $\alpha$-L-rhamnopyranosyl-(1-2)- $\beta$-Dglucopyranoside and other anthocyanins from the tree Dacrycarpus dacrydioides. Acta Chem. Scand. 42:462-468; 1988.

[14] Andersen, Ø. M. Anthocyanins from reproductive structures in Pinaceae. Biochem. Syst. Ecol. 20:145-148; 1992.

[15] Abdel-Rahim, A. G.; Arthur, J. R.; Mills, C. F. Effects of dietary copper, cadmium, iron, molybdenum and manganese on selenium utilization by the rat. J. Nutr. 116:403-411; 1986.

[16] Lim, V. S.; Henriquez, H.; Seo, H.; Refetoff, S.; Martino, E. J. Thyroid function in an uremic rat model. J. Clin. Invest. 66:946954; 1980.

[17] Hess, D.; Keller, H. E.; Oberlin, B.; Bonfanti, R.; Schuep, W. Simultaneous determination of retinol, tocopherols, carotene and lycopene in plasma by means of high performance liquid chromatography on reversed phase. Int. J. Vitam. Nutr. Res. 61:232238; 1991.

[18] Pedersen, C. B.; Kyle, J.; Jenkinson, A. M.; Gardner, P. T.; McPhail, D. B.; Duthie, G. G. Effects of blueberry and cranberry juice consumption on the plasma antioxidant capacity of healthy female volunteers. Eur. J. Clin. Nutr. 54:405-408; 2000.

[19] Jiang, Z. Y.; Woollard, A. C.; Wolff, S. P. Lipid hydroperoxide measurement by oxidation of $\mathrm{Fe}^{2+}$ in the presence of xylenol orange. Comparison with the TBA assay and an iodometric method. Lipids 26:853-856; 1991.

[20] Wood, S. G.; Gedik, C. M.; Vaughan, N. J.; Collins, A. R. Measurement of 8-oxo-deoxyguanosine in lymphocytes, cultured cells and tissue samples by HPLC with electrochemical detection. Methods Mol. Med. 38:171-178; 2000.

[21] Duthie, G. G.; Gonzalez, B. M.; Morrice, P. C.; Arthur, J. R. Inhibitory effects of isomers of tocopherol on lipid peroxidation of microsomes from vitamin E-deficient rats. Free Radic. Res. Commun. 15:35-40; 1991.

[22] Levi, F.; Pasche, C.; Lucchini, F.; La Vecchia, C. Dietary intake of selected micronutrients and breast-cancer risk. Int. J. Cancer 91:260-263; 2001.

[23] Michaud, D. S.; Spiegelman, D.; Clinton, S. K.; Rimm, E. B.; Willett, W. C.; Giovannucci, E. Prospective study of dietary supplements, macronutrients, micronutrients, and risk of bladder cancer in US men. Am. J. Epidemiol. 152:1145-1153; 2000.

[24] Helzlsouer, K. J.; Huang, H. Y.; Alberg, A. J.; Hoffman, S.; Burke, A. Norkus, E. P.; Morris, J. S.; Comstock, G. W. Association between alpha-tocopherol, gamma-tocopherol, selenium, and subsequent prostate cancer. J. Natl. Cancer Inst. 92:2018-2023; 2000.

[25] Shklar, G.; Oh, S. K. Experimental basis for cancer prevention by vitamin E. Cancer Invest. 18:214-222; 2000.

[26] Sarma, A. D.; Sharma, R. Anthocyanin-DNA copigmentation complex: mutual protection against oxidative damage. Phytochemistry 52:1313-1318; 1999.

[27] Seis, H.; Stahl, W.; Sundquist, A. R. Antioxidant function of vitamins: vitamin $\mathrm{E}$ and $\mathrm{C}$, beta-carotene and other carotenoids. Ann. N.Y. Acad. Sci. 669:7-20; 1992.

[28] Dangles, D.; Dufour, C.; Fargeix, G. Inhibition of lipid peroxidation by quercetin and quercetin derivatives: antioxidant and pro-oxidant effects. J. Chem. Soc. [Perkin 2] 2:1215-1222; 2000.

[29] Rice-Evans, C.; Leake, D.; Bruckdorfer, K. R.; Diplock, A. T. Practical approaches to low density lipoprotein oxidation: whys, wherefores and pitfalls. Free Radic. Res. 25:285-311; 1996. 